Mеталлофиз. новейшие технол. / Metallofiz. Noveishie Tekhnol. @ 2018 ИМФ (Институт металлофизики 2018 , т. 40, № 6, сс. 759-776 / DOI: 10.15407/mfint.40.06.0759 им. Г. В. Курдюмова НАН Украины) Оттиски доступны непосредственно от издателя

Фотокопирование разрешено только

Напечатано в Украине.

в соответствии с лицензией

PACS numbers: 61.05.cc, 61.05.cp, 68.35.Ct, 68.65.Ac, 68.65.Cd, 68.65.Fg, 81.05.Ea

\title{
Simulation of X-Ray Diffraction Spectra for AlN/GaN Multiple Quantum Well Structures on AlN(0001) with Interface Roughness and Variation of Vertical Layers Thickness
}

\author{
O. I. Liubchenko and V. P. Kladko \\ V. E. Lashkaryov Institute of Semiconductor Physics, N.A.S. of Ukraine, \\ 41 Nauky Ave., \\ UA-03028 Kyiv, Ukraine
}

\begin{abstract}
A detailed XRD analysis of $\mathrm{AlN} / \mathrm{GaN}$ multiple quantum well (MQW) structures grown on AlN(0001) substrates is proposed. The effect of roughness on the $2 \theta-\omega$ scans measured in Bragg diffraction for symmetrical reflections is investigated together with the effect of depth variation of the well and barrier thickness. As shown, the magnitude of depth variation of the well and barrier thickness results in an asymmetrical broadening of the satellite peaks of the 2 $\theta-\omega$ scans. Roughness causes their symmetrical expansion that allows separating the influence of both effects. Several reasons of asymmetrical broadening of satellite peaks are considered: variation of the thickness period, variation of the average lattice parameter inherent to the period, which depends on the thickness ratio of the layers in the period, and their combination. The efficiency of the described method is illustrated in detail by numerical simulations.
\end{abstract}

Key words: dynamical X-ray diffraction, multiple quantum well structure, thickness variation with depth, computer simulation, superlattice.

В роботі проведено детальну аналізу структур із множинними квантовими ямами (MКЯ) AlN/GaN, вирощених на підкладинках AlN(0001). Було досліджено вплив шерсткости та зміни товщини шарів структури з МКЯ

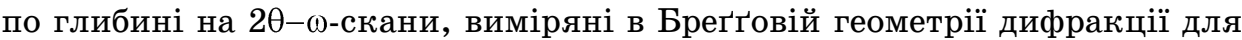
симетричних рефлексів. Показано, що зміна товщини квантових ям i

Corresponding author: Oleksii Ihorovich Liubchenko

E-mail: lubchenco.a@gmail.com

Citation: O. I. Liubchenko and V. P. Kladko, Simulation of X-Ray Diffraction Spectra for AlN/GaN Multiple Quantum Well Structures on AlN(0001) with Interface

Roughness and Variation of Vertical Layers Thickness, Metallofiz. Noveishie Tekhnol., 40, No. 6: 759-776 (2018), DOI: 10.15407/mfint.40.06.0759. 
бар’єрів по глибині приводить до асиметричного розширення сателітних

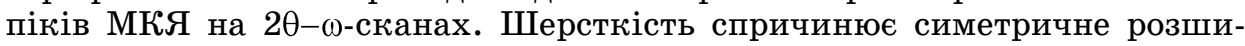
рення піків, що уможливлює розрізнити вплив цих ефектів. Розглянуто кілька причин асиметричного розширення сателітних піків: зміну товщини періоду, зміну середнього параметра гратниці періоду, який залежить від співвідношення товщин шарів періоду, та їх комбінації. Ефективність розробленої методи показано шляхом числового моделювання рентгенівських спектрів.

Ключові слова: динамічна дифракція X-променів, множинні квантові ями, зміна товщини по глибині, комп'ютерне моделювання, надгратниця.

В работе предложен детальный рентгенодифракционный анализ структур с множественными квантовыми ямами (MКЯ) $\mathrm{AlN} / \mathrm{GaN}$, выращенными на подложках AlN(0001). Было исследовано влияние шероховатости и вариации толщины слоёв квантовых ям и барьеров на $2 \theta-\omega$-сканы, полученные в геометрии отражения по Брэггу для симметричных рефлексов. Показано, что наличие вариации толщины слоёв AlN и $\mathrm{GaN}$ по глубине приводит к появлению асимметрии сателлитных пиков МКЯ на 20-юсканах. Наличие шероховатости приводит к симметричному расширению сателлитных пиков, что позволяет разделить влияние этих эффектов. Рассмотрено несколько причин асимметричного расширения сателлитных пиков: изменение толщины периода, изменение среднего параметра решётки периода, который зависит от соотношения толщин слоёв в периоде, и их комбинации. Эффективность разработанного метода показана с помощью численного моделирования.

Ключевые слова: динамическая дифракция рентгеновских лучей, множественные квантовые ямы, изменение толщины по глубине, компьютерное моделирование, сверхрешётка.

(Received April 6, 2018)

\section{INTRODUCTION}

Multiple quantum well (MQW) structures and superlattices based on III-nitrides are extensively used in light emitting diodes with high luminescent efficiency (LEDs) and laser diodes for various applications in photonic devices operating in a wide optical range [1-6]. Specifically, AlN/GaN MQW structures are used for LEDs emitting in the visible-ultraviolet spectral range [1, 7] and solid-state THz optoelectronics $[8,9]$. Investigation and development of these materials and devices requires advanced materials' characterization techniques examining structural, optical, and electronic properties. Optical characteristics of devices based on MQW structures essentially depend on structural parameters such as the thickness of barrier/quantum well layers [2, 3, $6,10]$. Any variation in the well or barrier width with the depth or in plane during growth can therefore modify the electronic characteris- 
tics. In addition, because of the small thickness of recent QW (few nanometres), variations in the thickness of only one monolayer are sufficient to lead to large changes in the interband and intersubband transitions energies [11-13].

Therefore, a comprehensive structural characterization of the MQW structures is needed to optimize the growth process and device performance. The laboratory high-resolution X-ray diffraction (HRXRD) is a rapid, non-destructive and low-cost technique widely used for characterization of III-nitrides [14-22]. In the theoretical description of Xray diffraction in MQW structures, thin and ion-implanted layers, both dynamical and kinematical approaches were used [21, 23]. The main approaches to model X-ray diffraction patterns from MQW structures are layer-by-layer simulation [24] and the period-by-period simulation [21]. For both approaches, it is often assumed that all periods in MQWs are equal. However, only the layer-by-layer modelling approach can also be used to study vertical structure inhomogeneities. The analysis of HRXRD data is often based on the Takagi-Taupin equations [25-27] or their derivatives [23, 28]. The Takagi-Taupin equations are based on the dynamical theory of X-ray diffraction, which assumes that the structures are crystallographically perfect (or almost perfect) with very small fluctuations of lattice displacements and suits well for high-quality epitaxial structures study.

In recent experimental studies of MQW structures, especially structures based on III-nitrides, an asymmetry of the peaks and a much larger peak broadening in X-ray diffraction spectra are observed in comparison with theoretically calculated spectra based on conventional diffraction models [3, 29]. Several different features cause these effects: variation of the in-plane lattice parameter [30], dislocations [18, $31]$, roughness [19, 32, 33], interface grading, changes in the thickness of layers from the substrate to the surface and on the area of the sample.

Previous studies were focused on the investigation of the effect of interface grading and lateral thickness variation [32], MQW structure lateral lattice parameter variation $[19,32]$, but the effect of the vertical variation of the layers thickness is poorly explored from the viewpoint of modern methods of HRXRD [33] and requires further investigations. Commercial programs allow simulating spectra by using conventional models of the diffraction, taking into account the effect of interface grading, while the simulation of X-ray spectra, which consider the effects of lattice parameter variation or variation in the layer thickness, is often complicated or impossible.

Therefore, in this paper, the effect of thickness variation with depth and interface roughness from MQW structures on the $2 \theta-\omega$ scans in the symmetrical Bragg case is investigated using dynamical diffraction simulation. 


\section{EXPERIMENTAL}

The samples investigated in this paper were grown by plasma-assisted MBE on a template that consists of a $600 \mathrm{~nm} \mathrm{AlN} \mathrm{layer} \mathrm{on} \mathrm{an} \mathrm{Al}_{2} \mathrm{O}_{3}$ (0001) substrate. The GaN/AlN MQW structures were grown at the substrate temperature of about $690^{\circ} \mathrm{C}$. First, a $100 \mathrm{~nm}$ undoped GaN buffer layer was grown on the template, followed by the deposition of a 10 and 20 periods MQW structure, samples S10 and S20, respectively. Finally, the samples were capped by $10 \mathrm{~nm}$ of GaN. The nominal thickness of the AlN barriers and GaN QW layers was $3 \mathrm{~nm}$ and $5 \mathrm{~nm}$, respectively.

High-resolution X-ray diffraction (HRXRD) was performed using a PANalytical X'Pert Pro MRD XL diffractometer (delivering $\mathrm{Cu} K_{\alpha 1}$ radiation with $\lambda=0.154056 \mathrm{~nm}$ ) equipped with the fourfold (220) Ge monochromator and threefold (022) Ge analyser in front of a proportional point detector.

\section{THEORY}

The XRD spectra for the multiple quantum well structures were simulated using the dynamical theory of X-ray diffraction described by the Takagi-Taupin equation [23, 25-28]. A complete description of the dynamical theory used in this paper can be found in Ref. [28]. The solution of the Takagi-Taupin equation is used to calculate the X-ray complex scattering amplitude $X$ :

$$
-\frac{i d X}{d T}=X^{2}-2 \eta X+1 .
$$

$T$ is the normalized coordinate perpendicular to the crystal surface:

$$
T=\frac{\pi C t \sqrt{\chi_{H} \chi_{\bar{H}}}}{\lambda \sqrt{\left|\gamma_{0} \gamma_{H}\right|}},
$$

and $\eta$ is the deviation parameter:

$$
\eta=\frac{\gamma_{0} \alpha+\frac{1}{2} \chi_{0}(1-b)}{\sqrt{|b|} C \sqrt{\chi_{H} \chi_{\bar{H}}}},
$$

where $C$ is the polarization factor, which is equal to unity for $\sigma$ polarization and $\cos (2 \theta)$ for $\pi$ polarization, $\chi_{0}$ and $\chi_{H}$ are electric susceptibilities, which are related to the structure factor of the crystal unit cell, $\gamma_{0}$ and $\gamma_{H}$ are the direction cosines of the incident and reflected beams with respect to the crystal-surface normal, $b$ is the asymmetry factor, 
$t$-the layer thickness, $\lambda$-the X-rays' wavelength, and $\alpha$-the deviation parameter.

The conventional deviation parameter was shown to fail at the angular distances far from the Bragg position, thus an improved function for $\alpha$ introduced by Zaus [28] was used:

$$
\alpha=(\Delta \theta) \frac{\sin \left(2 \theta_{B}\right)}{\sin \left(\theta_{B}+\phi\right)}+\frac{1}{2}(\Delta \theta)^{2}\left(\frac{\cos \left(2 \theta_{B}\right)}{\sin \left(\theta_{B}+\phi\right)}-\frac{\sin ^{2}\left(\theta_{B}-\phi\right)}{\sin ^{3}\left(\theta_{B}+\phi\right)}\right) .
$$

Here, $\theta_{B}$ is the Bragg angle of the layer, $\phi$ - the inclination of the layer lattice planes relative to the surface, $\Delta \theta=\theta-\theta_{B}$-the deviation from the exact Bragg position, $\theta$ - the angle between the reflecting planes and the incident wave.

The direction cosines $\gamma_{0}$ and $\gamma_{H}$ in the case of the improved deviation parameter $\alpha$ are given as follow [28]:

$$
\gamma_{0}=\sin \left(\theta_{B}-\phi\right), \gamma_{H}=-\sin \left(\theta_{H}+\phi\right),
$$

where the angle of exit $\theta_{H}+\phi$ of the diffracted wave in vacuum is given in Ref. [28]:

$$
\cos \left(\theta_{H}+\phi\right)=\cos (\theta-\phi)-2 \sin \left(\theta_{B}\right) \sin (\phi) .
$$

Assuming that the layers are laterally uniform and all variations occur along the axis $z$ normal to the sample surface, the amplitude ratio $X_{i}$ at the top of the layer is related to the amplitude ratio $X_{i-1}$ at the bottom by [28]:

$$
\begin{gathered}
X_{i}=\eta+\sqrt{\eta^{2}-1} \frac{S_{1}+S_{2}}{S_{1}-S_{2}}, \\
S_{1,2}=\left(X_{i-1}-\eta \pm \sqrt{\eta^{2}-1}\right) \exp \left(\mp i T \sqrt{\eta^{2}-1}\right) .
\end{gathered}
$$

The reflected amplitude from multilayered structure was calculated starting from the bottom layer and assuming that below the bottom layer the complex scattering amplitude is equal to zero; or using complex scattering amplitude from the substrate and adding layers one-byone, using the recursion formula Eq. (7), until reaching the surface of the uppermost layer. Finally, Ref. [28] gives the reflectivity:

$$
R=\left|\frac{\chi_{H}}{\chi_{\bar{H}}}\right|\left|X_{N}\right|^{2},
$$

where $X_{N}$ is the complex scattering amplitude of the upper layer.

The main advantage of this diffraction model is its simplicity and, consequently, a high computing speed. The disadvantage of the model 
is a large number of simplifications, which lead to deterioration in the quality of physical description of the diffraction phenomenon. For even more accelerated computations, we developed a program for XRD spectra simulation by using the $\mathrm{C}++$ programming language and NVIDIA CUDA parallel computing technology.

Within the framework of the above discussion, the MQW structure was considered as a stack of $N$ layers. Investigating the effect of thickness variation was carried out by substitution of the thickness value in Eq. (2) in the form $t=t_{0}+\Delta t$, where $t_{0}$ is a given constant thickness for each layer in the MQW period (averaged constant value), and $\Delta t$ is the additive part of the thickness, which can vary by arbitrary law from substrate to surface of the investigated MQW structure (depending on the structure depth). We used the exponential form of $\Delta t$, which is given by

$$
\Delta t=K_{1} \exp \left(-K_{2} N\right),
$$

where $N$ is the period number (the periods are counted from the substrate to the top of the layer stack), $K_{1}$ and $K_{2}$ are parameters that specify variation of the thickness.

In Equation (4), the angles $\theta$ and $\theta_{B}$ are incidence and Bragg angles for the respective layer. If the Bragg plane of the substrate is chosen as a common plane of reference, then for these layers, Ref. [28] gives the deviation $\theta_{B}$ :

$$
\Delta \theta=\theta-\theta_{B s}+\delta \theta,
$$

where $\theta_{B s}$ is the Bragg angle for the substrate, and the change of the Bragg angle is [28, 34]

$\delta \theta=$

$$
=\left(\left.\frac{\Delta d}{d}\right|^{\perp} \cos ^{2}(\phi)+\left.\frac{\Delta d}{d}\right|^{\|} \sin ^{2}(\phi)\right) \tan \left(\theta_{B s}\right)+\left(\left.\frac{\Delta d}{d}\right|^{\perp}-\left.\frac{\Delta d}{d}\right|^{\|}\right) \cos (\phi) \sin (\phi),
$$

where $\left.\frac{\Delta d}{d}\right|^{\perp, \|}$ are the in- and out-of-plane mismatches of interplanar spacing between the layer and the substrate.

\section{RESULTS AND DISCUSSION}

Theoretical simulations of symmetrical $2 \theta-\omega$ scans were performed for the tested sample consisting of a 20 period AlN/GaN MQW structure $(5 \mathrm{~nm} / 5 \mathrm{~nm})$ (layers A and B) on the AlN/GaN (600 nm/100 nm) buffer grown on an $\mathrm{Al}_{2} \mathrm{O}_{3}(0001)$ substrate. 


\begin{tabular}{|l|}
\hline GaN $\}$ AlN/GaN MQW structure, \\
\hline AlN \\
\hline $100 \mathrm{~nm}$ GaN buffer layer \\
\hline $600 \mathrm{~nm}$ AlN buffer layer \\
\hline Sapphire (0001) \\
\hline
\end{tabular}

Fig. 1. Schematic sketch of MQW structure.

To investigate the influence of different kinds of thickness variations theoretically, we assume here that the GaN buffer layer and the GaN layers in the MQW are fully strained to the AlN buffer layer and that the AlN layers are fully relaxed. Figure 1 shows a sketch of the

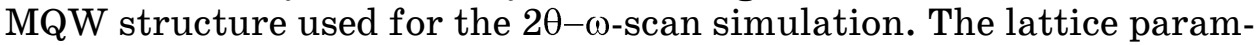
eters of bulk GaN and AlN were taken from Ref. [35]. For strained GaN layers, the lattice parameter $c$ was recalculated from $a$ according to Refs. [16, 35]. The electric susceptibilities were taken from Stepanov's $\mathrm{X}$-ray server [36]. The instrumental function is approximated by the Gaussian profile with the full width at half maximum (FWHM) 12 arcsec that corresponds to FWHM of the rocking curve of analyser crystal.

\subsection{Influence of Thickness Variation}

Various cases of the thickness variation $\Delta t$ for the barrier (layer A) and QW (layer B) layers in the MQW structure were investigated according to Eq. (10).

First, using Eq. (10), we explore the variation of the MQW period thickness with increasing distance from the substrate (to the sample surface). For this purpose, we simultaneously change the thickness of both layers $\mathrm{A}$ and $\mathrm{B}$. The thickness ratio between the layers $\mathrm{A}$ and $\mathrm{B}$ does not change with depth; whereas, the addition to the thickness of both layers $\Delta t$ have the same sign and magnitude. As the average lattice parameter of the period (Eq. (13)) depends on the lattice parameters of both layers and their thickness ratio [16, 18, 37], it does not change with depth:

$$
c_{a v}=\frac{c_{\mathrm{A}} t_{\mathrm{A}}+c_{\mathrm{B}} t_{\mathrm{B}}}{t_{\mathrm{A}}+t_{\mathrm{B}}},
$$

where $c_{\mathrm{A}, \mathrm{B}}$ and $t_{\mathrm{A}, \mathrm{B}}$ are the lattice parameters and thickness of layers $\mathrm{A}$ and $\mathrm{B}$ in the MQW structures.

Figure 2 shows the simulated $2 \theta-\omega$ scans of the symmetrical (0002) reflection $(a)$, and the thickness profile of each period used for the simulation (b). Two cases were considered: 1 ) a thickness change with larger magnitude on the side of the substrate with a positive value of $\Delta t ; 2)$ a thickness change with larger magnitude on the surface side 


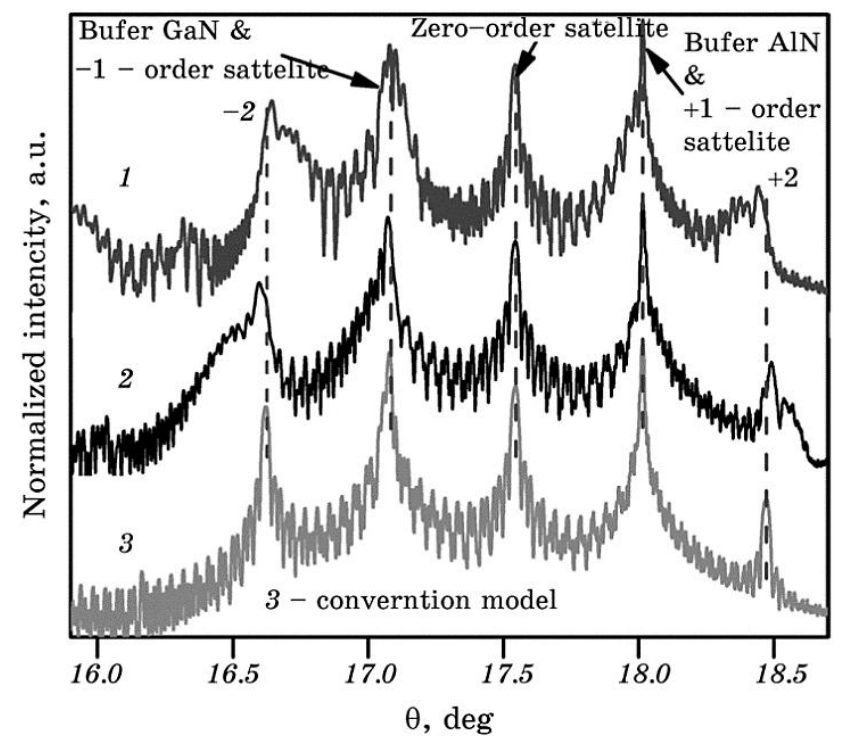

$a$

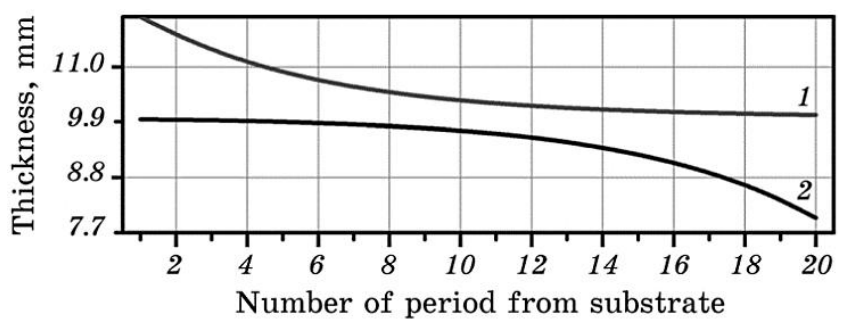

$b$

Fig. 2. The 2 $\theta-\omega$ scans of (0002) reflection for different cases of period thickness variation ( 1 and 2 ) and calculated using the conventional model $(a)$; depth profiles of variation in the period thickness $(b)$.

with a negative value of $\Delta t$ (Fig. $2, b)$. It was observed that, when the thickness of the periods in the MQW structure varies, the shape of one satellite peak (here, the zero-order peak) does not change. Subsequently, we will call this peak as unchanged shape satellite. For other satellite peaks, an asymmetry of the peak shape is observed, which depends on the sign and magnitude of $\Delta t$.

First, we discuss the influence of a positive value of $\Delta t$. In this case for the satellite peaks lying at lower angles than the unchanged shape satellite (indicated on the spectra as $-1,-2,-3$ ), the asymmetry is more pronounced on the higher-angle side of each peak. Satellite peaks at larger angles than the unchanged shape satellite $(1,2,3)$ have a clearly visible anisotropy on their low angle shoulder. If the value of $\Delta t$ is neg- 
ative, the asymmetric broadening of the peak shape is on the opposite shoulder than in case of a positive $\Delta t$. In other words, for positive $\Delta t$, the asymmetry of the satellite peaks arises from the side of the unchanged shape satellite, and where the addition $\Delta t$ is negative, asymmetry emerges on peak shoulders pointing away from the unchanged shape satellite.

The asymmetry effect is more pronounced for distant satellites relative to the unchanged shape one. In addition, there is a small angular displacement of the satellite peaks, accompanied by an increase of the peak width and a decrease of the intensity on direction of the asymmetric broadening. At the same time, satellites, which were not observed due to attenuation conditions [18], like the missing satellite of $-3^{\text {rd }}$ order in Fig. 2, $a$, may become clearly visible. It should be noted that the XRD spectra weakly vary in dependence of the period change direction (from the substrate or from the surface). The differences are better visible for low intense satellite peaks that are more distant from the unchanged shape satellites. The main differences between positive and negative $\Delta t$ are manifested in high-frequency intensity oscillations, which are poorly visible for this test sample due to the superposition with high-frequency thickness oscillations from the buffer layers.

However, determining the side of a greater thickness change may be possible for spectra with a clearly visible thin satellite structure. In this case, the reason for the asymmetry is the variation of the period thickness according to a certain law. The average lattice parameter of the period, which depends on the layers thickness ratio, does not change.

Different changes of the diffraction pattern can be observed (Fig. 3) when the thickness of the layers A and B varies with the opposite sign but the same magnitude of $\Delta t$ (in antiphase). In this case, the thickness of all GaN/AlN periods is constant, and according to Eq. (13), the average lattice parameter of the period changes with depth in dependence on the thickness ratio between the layers A and B. Figure 3 shows the $2 \theta-\omega$ scans of the symmetrical (0002), (0004), (0006) reflections ( $a-$ $c$-black), which correspond to the thickness variation shown in Fig. 3, $d$ and are compared with the $2 \theta-\omega$ scans (grey) of GaN/AlN layers of constant thickness through the whole sample. In the case of thickness variations as described above, the unchanged shape satellite vanishes, and all reflections and satellite peaks of this MQW structure have asymmetry. The peak asymmetry depends on the sign and magnitude of $\Delta t$, and for the thickness profiles in Fig. 3, $d$, the peaks are broadened asymmetrical toward the higher angles. When the thickness variation $\Delta t$ of the AlN and GaN layers has opposite signs, the satellites peaks are broadened toward the lower angles on the $2 \theta$ axis (not shown). From the spectra of different symmetrical reflections in Figs. $3, a-c$, it is clear that with increasing diffraction order the satellite 


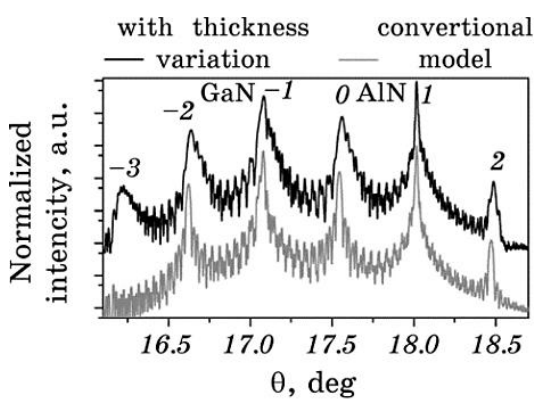

$a$

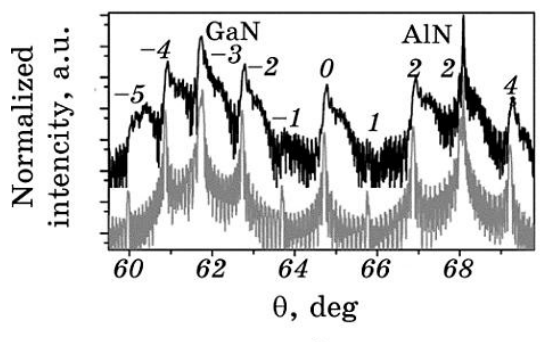

$c$

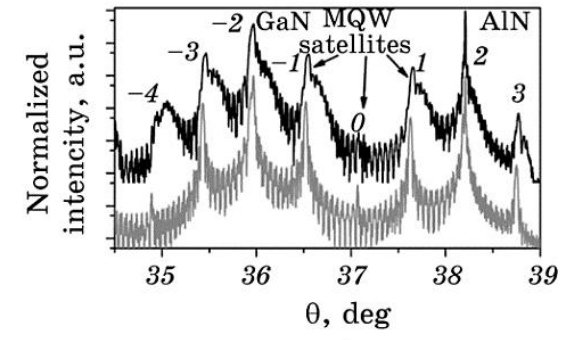

$b$

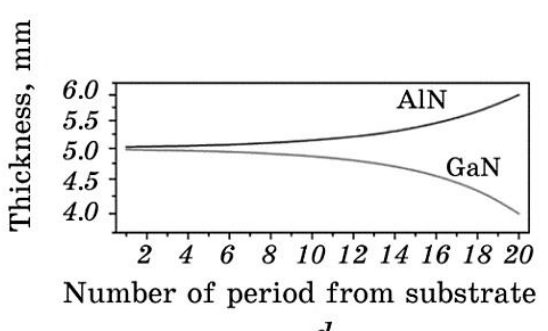

$d$

Fig. 3. The $2 \theta-\omega$ scans of (0002) ( $a)$, (0004) $(b)$ and (0006) $(c)$ reflections corresponding to depth profiles for AlN and GaN layers thickness $(d)$ calculated with thickness variation (black) and using the conventional model (grey).

peak asymmetry also increases. Other features of the satellites asymmetry behave as in the previous case. In this case, the reason for the asymmetry of all satellites is the change of the average lattice parameter of each period, which is caused by simultaneous change in the thickness of layers.

Next, we consider the interstitial case when the thickness of only one layer in the period (A or B) changes. This results in change of the period thickness and a change of the average lattice constant of each period with increasing distance from the buffer layer. In addition, the magnitude of the thickness change per period is two-times lower than in the case when the thickness changes simultaneously for both layers. Obviously, the change in the average lattice parameter of the period is also smaller. The mutual influence of changes in the thickness and average lattice parameter leads to a MQW structure satellite's asymmetry, which depends on the sign of $\Delta t$ and the law of its change. Furthermore, the unchanged shape satellite has a slightly different angular position than in the previous case of period's thickness change. When the thickness of the GaN layers in the MQW structure changes, the angular position of the unchanged shape satellite is close to the reflection of a single GaN layer with the same lattice parameters (and state of relaxation) as in the GaN layers in the MQW structure. For 
different-order reflections, the peak position of the GaN buffer layer is close to the angular position of the unchanged shape satellite, whose order also depends on the reflection order. For the case of thickness variation of GaN layers in the MQW considered in this section, the unchanged shape satellite has $-1^{\text {st }}$-order for $(0002)$ reflection, $-2^{\text {nd }}$-order for (0004) reflection, and $-3^{\text {rd }}$-order for (0006) reflection. Similarly, when only the thickness of AlN layers in MQW varies, the angular position of the unchanged shape satellite is close to the peak position of a AlN buffer layer whose lattice parameters is the same as in the AlN layers in the MQW. Applying this to our test structure, this means that, when the thickness of GaN layers changes with depth, the angular position of the unchanged shape satellite is close to the angular position of the GaN buffer layer of the investigated symmetrical reflections. It should be noted that this arrangement of the unchanged shape satellite peaks relative to the peak of the buffer layers is preserved only for fully strained or relaxed the AlN (GaN) MQW layers and AlN $(\mathrm{GaN})$ buffer layer, respectively. Other features of the satellites asymmetry are the same as in the previous case but less pronounced because the addition $\Delta t$ has a lower magnitude. Thus, the mutual influence of period thickness variation and the change of the average lattice parameter of the period lead to the appearance of satellites with unchanging shape and with displaced angular positions relative to the zero-order satellite and asymmetry of other satellites.

Our simulations have shown that, when the thickness of layers in the MQW structure changes with depth, the thickness ratio of quantum well/barrier layers and the average lattice parameter over the periods in the MQW structure vary as well. This leads to different asymmetry of the satellite peak. Therefore, thickness variation in the MQW structure layers is one of the reasons for asymmetry of the satellite peaks in $2 \theta-\omega$ scans.

\subsection{Influence of Random Thickness Fluctuation}

During the growth of MQW structures, interface roughness can lead to local fluctuations in the thickness of each layer. To consider the interface roughness, the following model similar to that described in Ref. [32] was developed.

We split the sample into a large number of crystallites with random thickness values of $\Delta t$ for each layer in each crystallite. The resulting spectrum was obtained as the averaged sum of the reflected intensities from the crystallites. We considered the case of normal distribution of random values of $\Delta t$. The generation of random numbers was done using the mt19937 random Number generator from the free library in $\mathrm{C}++$. Figure 4 shows the effect of roughness on the $2 \theta-\omega$ scans of our MQW test structure. The increase of roughness leads to a broadening 


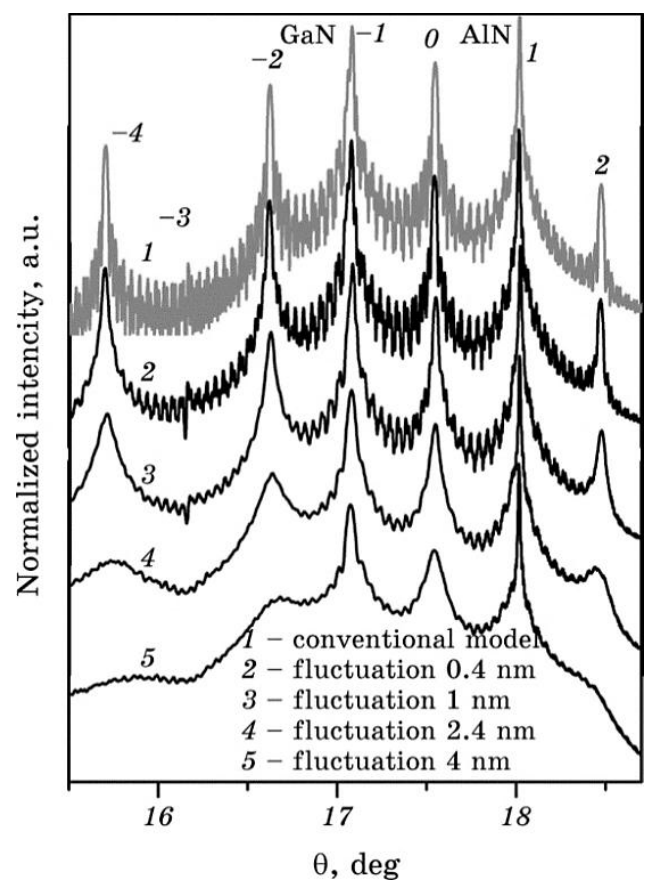

Fig. 4. The 2 $\theta-\omega$ scans of (0002) reflection for different magnitudes of thickness fluctuation.

of the satellite peaks with simultaneous reducing the amplitude of the thickness oscillations. The amplitude is even more reduced for distant satellites as compared with central satellites (-1, 0, 1-orders). Figure 5 shows the effect of thickness fluctuation on the spectra of various symmetrical reflections. The decrease of the oscillation amplitude is also observed with the increase of the reflection order.

Therefore, roughness can be one of the reasons for a significant expansion of satellites in the $2 \theta-\omega$ scan of the highest order reflections.

\subsection{Comparing the Theory and Experimental Data}

The theoretical framework described in the previous section has been applied for the investigation of GaN/AlN MQW structures grown on the $\mathrm{AlN} / \mathrm{GaN}$ buffer layer. In contrast to the theoretical calculations demonstrated in the previous sections, the relaxation state of real MQW should be considered for accurate simulation.

Therefore, the in-plane lattice parameters of the MQW $\left(a_{S L}\right)$ and AlN buffer layer $(a)$ of samples S10 and S20 were determined from the reciprocal space map (RSM) of the asymmetric (12)33) reflection [16]. For both samples, the measured parameters are $a_{S L}=0.31283 \mathrm{~nm}$ and 


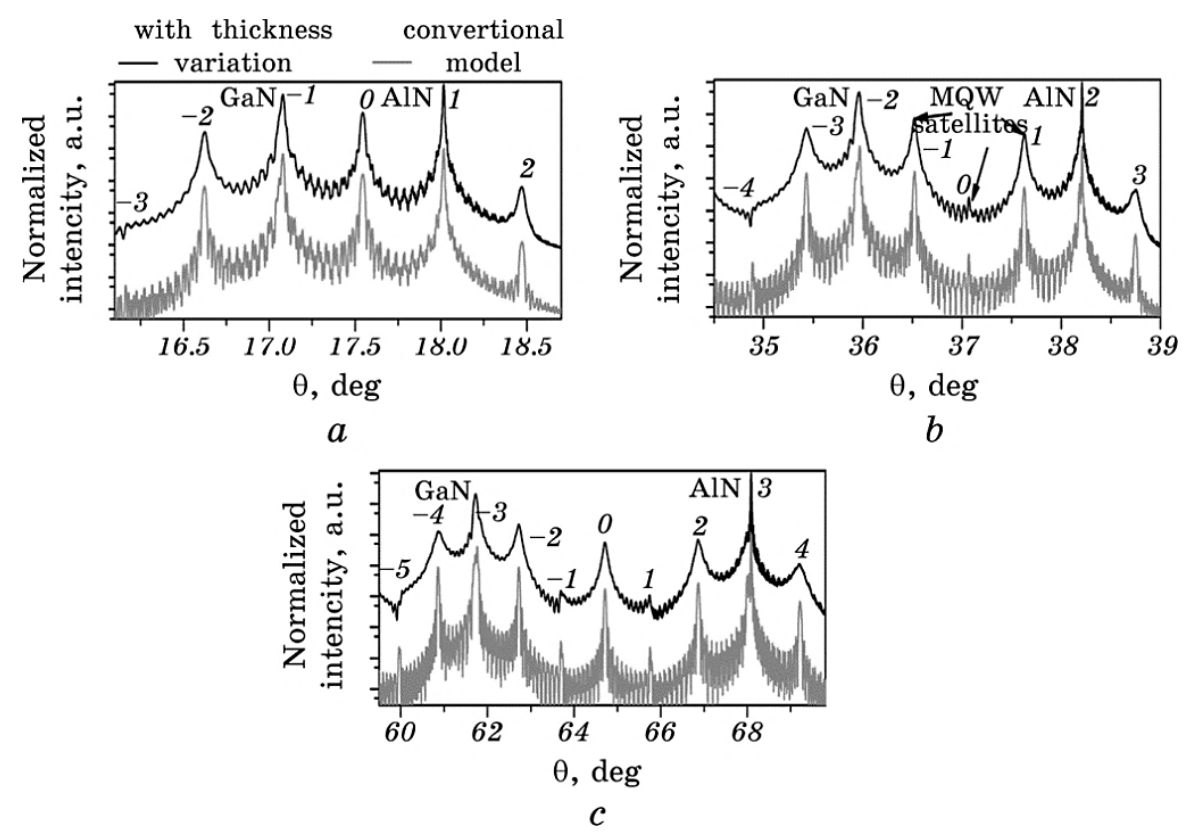

Fig. 5. The 2 $\theta-\omega$ scans of (0002) (a), (0004) (b) and (0006) (c) reflections with the same thickness fluctuation $1 \mathrm{~nm}$ (black) and $2 \theta-\omega$ scans obtained using the conventional model (grey).

$a=0.31007 \mathrm{~nm}$. Consequently, the AlN buffer layer is slightly compressed along the $a$-axis. The MQW lattice parameter $a_{S L}$ is closer to that of bulk AlN ( $a=0.31113 \mathrm{~nm}$ ) than to the $a$-parameter of $\mathrm{GaN}$ $(0.31893 \mathrm{~nm})$. It indicates that $\mathrm{GaN}$ layers are in a compression state (mismatch $\cong 1.9 \%$ ), which has much larger magnitude than the tensile stress of AlN layers. The out-of-plane lattice parameter $c$ was recalculated from $a$ according to Refs. [16, 35].

The $2 \theta-\omega$ scans of (0002) reflection (samples S10 and S20) are shown in Figs. 6, $a, c$, respectively. The figures show also the best fits using the developed model considering a variation in the thickness and the conventional model with a nominal thickness of the layers. The depth profiles of thickness variation for both layers in the MQW structures of the samples S10 and S20 are shown in Figs. 6, $b$ and $d$. Since the peak from the GaN buffer layer is almost invisible, it is not taken into account for the simulation. The simulation using the conventional model showed a significant asymmetric broadening of satellite peaks, revealing thickness values of $4 \mathrm{~nm}$ and $5.5 \mathrm{~nm}$ for AlN and GaN layers, respectively. Simulation of the spectra by using the developed model showed significant variation of the thickness. The roughness determined by simulation was $1-2$ atomic layers $(\cong 0.3 \mathrm{~nm}$ to $0.5 \mathrm{~nm})$. In the investigated spectra, roughness mainly influences the intensity of the 
$-2^{\text {nd }}-$ order satellite.

The minimization methods and fitting procedure are described in details in our previous work [38] for the case of implanted layers. We used the Hooke-Jeeves direct search algorithm for fitting the spectra. The error function is given by

$$
\operatorname{Err}=\sum_{j=1}^{N}\left|I_{j}^{\exp }-I_{j}^{\text {calc }}\right|^{k},
$$

where $I_{j}^{\exp }$ and $I_{j}^{\text {calc }}$ are experimental and calculated intensity values over all experimental points, $k$ is the power index (we use $k=0.1-0.8$ ), by which one can set the part of the spectrum that should be fitted better. At lower values of $k$, the 'tails' of the spectrum are better fitted, while the larger $k$ promotes a better fit of the peaks.

The average relative error calculated for all points of the experimental and fitted spectra (Eq. (15)) was $30-40 \%$ that is caused by the noise, background, and high-frequency oscillation through the thickness of buffer layers in the spectrum:

$$
\operatorname{Err}_{\text {rel }}=\frac{1}{N} \sum_{j=1}^{N} \frac{\left|I_{j}^{\text {exp }}-I_{j}^{\text {calc }}\right|}{I_{j}^{\exp }} .
$$

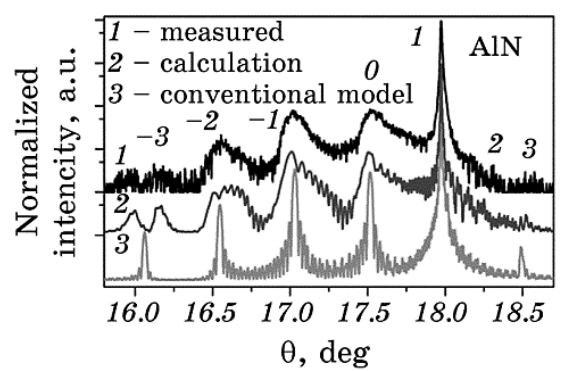

$a$

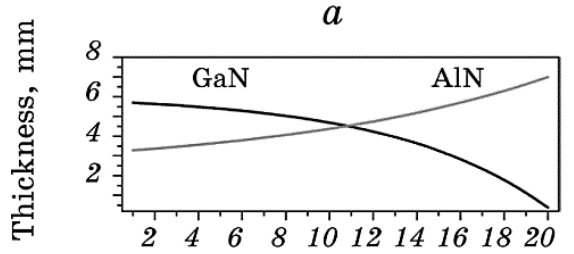

Number of period from substrate

$b$

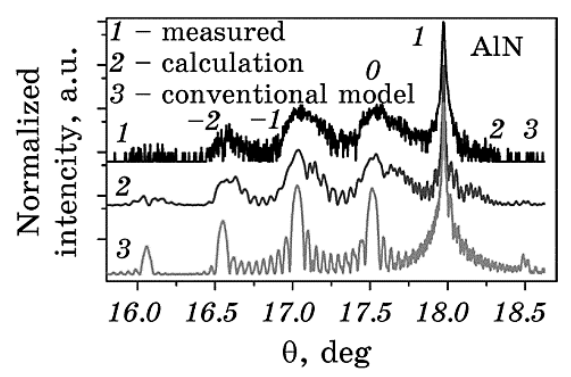

c

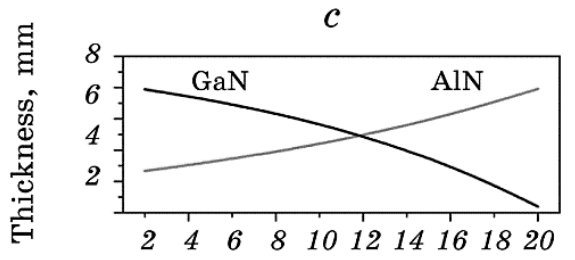

Number of period from substrate

$d$

Fig. 6. Comparison of the measured (1) and simulated $2 \theta-\omega$ scans of S20 (a) and S10 (c) samples using the developed (2) and conventional (3) models. The figures $b$ and $d$ show the depth profiles of thickness variation in the GaN QW and AlN barrier layers for the samples S20 and S10, respectively. 


\subsection{Discussion}

In general, it can be difficult to separate the influence of different MQW features (such as lateral thickness variation, lattice parameter variation, dislocations) on the XRD spectra. The peak width and shapes are commonly interpreted to be caused by a single dominant feature. Because of the integrity of XRD methods, spectra from MQW structures are sensitive to variations of the averaged lattice parameter, strains and any kind of thickness variations on significant area of the sample. As our examples showed, there is a significant asymmetry of satellites in the investigated samples. As shown above, thickness variation is the reason for this. Dislocations and lateral thickness variations cause only symmetrical broadening of satellites, like to that caused by roughness. Simulating the experimental spectra by using conventional model demonstrates the significant asymmetric peak broadening, especially in the sample S20. For real structures, many different features (listed above) are present simultaneously, but, in the investigated samples S10 and S20, the asymmetrical peak broadening is predominant.

The modelling of $2 \theta-\omega$ scans including thickness variation and the roughness shows a good coincidence with the experiment data, but other effects may exist, which can cause the peaks asymmetry or both the symmetrical and asymmetrical broadening. Simultaneous consideration of these effects together with considered above thickness variation and roughness goes beyond a scope of this work. The resulting depth profiles of the thickness can be explained by interpretation of the spectra, if taking into account only effects of thickness variation and roughness. It explains the significant values of thickness variation obtained using simulation.

It is also important to choose the type of $\Delta t$ function. The fitting procedure can be carried out for any form of $\Delta t$, but it is necessary to take into account the physical possibility of existence of this thickness variation. It is better to perform studies by using additional depth profiling methods such as secondary ion mass spectrometry or transmission electron microscopy, and then to use these data in XRD spectrum simulation. This approach can help to separate the influence of various effects on the spectrum and to investigate better their nature.

\section{SUMMARY AND CONCLUSIONS}

In this paper, a detailed X-ray diffraction analysis of the influence of layer thickness variation and thickness fluctuations for MQW structures was carried out. It was ascertained that variation of the thickness is one of the reasons for an asymmetry of satellite peaks. Variation of the period thickness with a constant ratio of $\mathrm{A}$ and $\mathrm{B}$ layer 
thickness leads to existence of the unchanged shape satellite and a different degree of the asymmetry for other satellites. If there is variation of thickness in both A and B layers in MQW structure, and herewith the period is kept constant, there is the asymmetry of all satellites. In the general case, there are both the asymmetry and the unchanged-shape satellite with angular position shifted relatively to the previous one. The size and side of the satellite asymmetry depends on the magnitude and sign of the layer thickness change. This asymmetry is clearer pronounced in distant-order satellites, and it increases for higher-order reflections. A random thickness fluctuation leads to smoothness and broadening of the satellites. These effects are also more pronounced for high-order satellites and significantly increase in higher-order reflections. Simulating of experimental spectra showed the necessity of using other independent methods for separating the investigated effects from others such as lateral thickness variation, lattice parameter variation, etc. Further studies should be performed to separate the listed above effects using other analytical methods in combination with XRD-methods.

\section{ACKNOWLEDGMENTS}

This work was funded by the Program of Fundamental Research of the National Academy of Sciences of Ukraine 'Fundamental Problems of New Nanomaterials and Nanotechnologies'. Furthermore, the authors thank PhD Hryhorii V. Stanchu and PhD Sergiy B. Kryvyi for useful discussions, and acknowledge Y. Polishchuk for critical reading of the manuscript.

\section{REFERENCES}

1. A. Kaminska, P. Strak, J. Borysiuk, K. Sobczak, J. Z. Domagala, M. Beeler, E. Grzanka, K. Sakowski, S. Krukowski, and E. Monroy, J.Appl. Phys., 119, No. 1: 015703 (2016).

2. X. Li, D. G. Zhao, D. S. Jiang, J. Yang, P. Chen, Z. S. Liu, J. J. Zhu, W. Liu, X. G. He, X. J. Li, F. Liang, J. P. Liu, L. Q. Zhang, H. Yang, Y. T. Zhang, G. T. Du, H. Long, and M. Li, Chinese Phys. B, 26, No. 1: 017805 (2017).

3. W. Liu, D. G. Zhao, D. S. Jiang, P. Chen, Z. S. Liu, J. J. Zhu, M. Shi, D. M. Zhao, X. Li, J. P. Liu, S. M. Zhang, H. Wang, and H. Yang, J. Alloys Compd., 625: 266 (2015).

4. P. M. McBride, Q. Yan, and C. G. Van De Walle, Appl. Phys. Lett., 105, No. 8: 083507 (2014).

5. J. Piprek and Z. M. Simon Li, Appl. Phys. Lett., 102, No. 2: 023510 (2013).

6. X. C. Wei, L. Zhang, N. Zhang, J. X. Wang, and J. M. Li, MRS Adv., 1, No. 2: 197 (2016).

7. A. Kaminska, D. Jankowski, P. Strak, K. P. Korona, M. Beeler, K. Sakowski, E. Grzanka, J. Borysiuk, K. Sobczak, E. Monroy, and S. Krukowski, J. Appl. 
Phys., 120, No. 9: 095705 (2016).

8. M. Beeler, C. Bougerol, E. Bellet-Amalric, and E. Monroy, Appl. Phys. Lett., 103, No. 9: 091108 (2013).

9. H. MacHhadani, Y. Kotsar, S. Sakr, M. Tchernycheva, R. Colombelli, J. Mangeney, E. Bellet-Amalric, E. Sarigiannidou, E. Monroy, and F. H. Julien, Appl. Phys. Lett., 97, No. 19: 191101 (2010).

10. M.-M. Liang, G.-E. Weng, J.-Y. Zhang, X.-M. Cai, X.-Q. Lü, L.-Y. Ying, and B.-P. Zhang, Chin. Phys. B, 23, No. 5: 054211 (2014).

11. M. Beeler, E. Trichas, and E. Monroy, Semicond.Sci. Technol., 28, No. 7: 074022 (2013).

12. H. Machhadani, P. Kandaswamy, S. Sakr, A. Vardi, A. Wirtmüller, L. Nevou, F. Guillot, G. Pozzovivo, M. Tchernycheva, A. Lupu, L. Vivien, P. Crozat, E. Warde, C. Bougerol, S. Schacham, G. Strasser, G. Bahir, E. Monroy, and F. H. Julien, New J. Phys., 11, No. 12: 125023 (2009).

13. P. K. Kandaswamy, F. Guillot, E. Bellet-Amalric, E. Monroy, L. Nevou, M. Tchernycheva, A. Michon, F. H. Julien, E. Baumann, F. R. Giorgetta, D. Hofstetter, T. Remmele, M. Albrecht, S. Birner, and L. S. Dang, J. Appl. Phys., 104, No. 9: 093501 (2008).

14. H. Rhan, U. Pietsch, S. Rugel, H. Metzger, and J. Peisl, J.Appl. Phys., 74, No. 1: 146 (1993).

15. O. Kolomys, B. Tsykaniuk, V. Strelchuk, A. Naumov, V. Kladko, Y. I. Mazur, M. E. Ware, S. Li, A. Kuchuk, Y. Maidaniuk, M. Benamara, A. Belyaev, and G. J. Salamo, J.Appl. Phys., 122, No. 15: 155302 (2017).

16. H. V. Stanchu, A. V. Kuchuk, M. Barchuk, Y. I. Mazur, V. P. Kladko, Z. M. Wang, D. Rafaja, and G. J. Salamo, Cryst.Eng. Comm., 19, No. 22: 2977 (2017).

17. J. Gaca and M. Wojcik, Appl. Phys. Lett., 65, No. 8: 977 (1994).

18. S. B. Kryvyi, P. M. Lytvyn, V. P. Kladko, H. V. Stanchu, A. V. Kuchuk, Y. I. Mazur, G. J. Salamo, S. Li, P. P. Kogutyuk, and A. E. Belyaev, J. Vac. Sci. Technol. B: Nanotechnol. Microelectron., 35, No. 6: 062902 (2017).

19. A. Chandolu, S. Nikishin, M. Holtz, and H. Temkin, J.Appl. Phys., 102, No. 11: 114909 (2007).

20. P. F. Fewster, V. Holy, and N. L. Andrew, Mater. Sci. Semicond. Process., 4, No. 6: 475 (2001).

21. R. N. Kyutt, A. Y. Khil'ko, and N. S. Sokolov, Phys. Solid State, 40, No. 8: 1417 (1998).

22. V. Kladko, A. Kuchuk, P. Lytvyn, O. Yefanov, N. Safriuk, A. Belyaev, Y. I. Mazur, E. A. DeCuir, M. E. Ware, and G. J. Salamo, Nanoscale Res. Lett., 7, No. 1: 289 (2012).

23. A. Sanz-Hervás, M. Aguilar, J. L. Sánchez-Rojas, A. Sacedyn, E. Calleja, E. Mucoz, C. Villar, E. J. Abril, and M. López, J.Appl. Phys., 82, No. 7: 3297 (1997).

24. V. I. Punegov, Phys. Status Solidi (a), 136, No. 1: 9 (1993).

25. S. Takagi, Acta Crystallogr., 15, No. 12: 1311 (1962).

26. S. Takagi, J. Phys. Soc. Japan., 26, No. 5: 1239 (1969).

27. D. Taupin, Bull. Soc. Franc. Mineral. Crystallogr., 7, No. 87: 469 (1964).

28. R. Zaus, J. Appl. Crystallogr., 26, No. 6: 801 (1993).

29. Y. Kotsar, B. Doisneau, E. Bellet-Amalric, A. Das, E. Sarigiannidou, and E. Monroy, J.Appl.Phys., 110, No. 3: 033501 (2011). 
30. E. Bellet-Amalric, C. Adelmann, E. Sarigiannidou, J. L. Rouvière, G. Feuillet, E. Monroy, and B. Daudin, J.Appl. Phys., 95, No. 3: 1127 (2004).

31. N. V. Safriuk, G. V. Stanchu, A. V. Kuchuk, V. P. Kladko, A. E. Belyaev, and V. F. Machulin, Semicond. Phys. Quantum Electron. Optoelectron., 16, No. 3 : 265 (2013).

32. S. R. Lee, D. D. Koleske, M. H. Crawford, and J. J. Wierer, J. Cryst. Growth, 355, No. 1: 63 (2012).

33. P. F. Fewster, J.Appl. Crystallogr., 21, No. 5: 524 (1988).

34. W. J. Bartels and W. Nijman, J. Cryst. Growth, 44, No. 5: 518 (1978).

35. D. J. Wallis, D. Zhu, F. Oehler, S. P. Westwater, A. Pujol, and C. J. Humphreys, Semicond. Sci. Technol., 28, No. 9: 094006 (2013).

36. S. Stepanov and R. Forrest, J.Appl. Crystallogr., 41, No. 5: 958 (2008).

37. N. J. Ekins-Daukes, K. Kawaguchi, and J. Zhang, Cryst. Growth Des., 2, No. 4: 287 (2002).

38. O. Liubchenko, V. Kladko, and Oy. Gudymenko, Semicond. Physics, Quantum Electron. Optoelectron., 20, No. 3: 355 (2017). 